\title{
Gulf Stream and Kuroshio Current are synchronized
}

\section{The atmospheric jet stream ties temperature variations of two distant ocean currents for the decadal time scale.}

\author{
Tsubasa Kohyama ${ }^{1 *}$, Yoko Yamagami ${ }^{2}$, Hiroaki Miura ${ }^{3}$,
} Shoichiro Kido $^{4}$, Hiroaki Tatebe ${ }^{5}$, and Masahiro Watanabe ${ }^{2}$

${ }^{1}$ Department of Information Sciences, Ochanomizu University, 2-1-1, Otsuka, Bunkyo-ku, Tokyo, 112-8610, Japan

${ }^{2}$ Atmosphere and Ocean Research Institute, The University of Tokyo, 5-1-5 Kashiwanoha, Kashiwa-shi, Chiba 277-0882, Japan

${ }^{3}$ Department of Earth and Planetary Sciences, The University of Tokyo,

7-3-1 Hongo, Bunkyo-ku, Tokyo 113-0033, Japan

${ }^{4}$ Application Laboratory (APL),

Japan Agency for Marine-Earth Science and Technology,

3173-25, Showa-cho, Kanazawa-ku, Yokohama-shi, Kanagawa 236-0001, Japan

${ }^{5}$ Research Center for Environmental Modeling and Application (CEMA),

Japan Agency for Marine-Earth Science and Technology,

3173-25, Showa-cho, Kanazawa-ku, Yokohama-shi, Kanagawa 236-0001, Japan

*E-mail: tsubasa@is.ocha.ac.jp

This manuscript has been submitted for publication in Science.

Please note that, despite being under peer-review,

the manuscript has yet to be formally accepted for publication.

Subsequent versions of this manuscript may have different content.

If accepted, the final version of this manuscript will be available via the 'Peer-reviewed Publication DOI' link on the right-hand side of this webpage.

Please feel free to contact any of the authors; we welcome feedback. 
Observational records show that sea surface temperatures along the Gulf Stream and Kuroshio tend to synchronize at decadal time scales. This synchronization, which we refer to as the Boundary Current Synchronization (BCS), is reproduced in global climate models with high spatial resolution. Both in observations and model simulations, BCS is associated with meridional migrations of the atmospheric jet stream. Changes in the strength and path of the ocean currents driven by the jet shifts lead to the synchronicity of surface temperatures. Numerical simulations using a conceptual model and an atmospheric general circulation model are consistent with a notion that BCS is an interbasin air-sea coupled mode. The abnormally hot summer in 2018 over the Northern Hemispheric extratropics is explained by the positive phase of BCS. 
The two warm ocean currents, the Gulf Stream and the Kuroshio, are located in the western boundaries of the Atlantic and the Pacific Oceans, respectively, so they are referred to as the western boundary currents (WBCs) (1-3). Meanderings of WBCs and the associated sea surface temperature (SST) variations have long been known to affect local weather and climate in the coastal metropolitan areas, mainly because WBCs transport heat from the tropics to the extratropics and modulate cyclogenesis (4) and low cloud formation (5). More recently, high-resolution satellite observations helped reveal that heat released from WBCs have profound impacts on the entire troposphere (6-8). The Gulf Stream and the Kuroshio are known as centers of action in the midlatitude intrinsic variability (9-11), and also serve as surface fingerprints of low-frequency natural climate variability (e.g., Atlantic Meridional Overturning Circulation (12), Pacific Decadal Oscillation (PDO) (13)). Thus, understanding WBCs have major implications for paleoclimatology (14), climate modeling (15), and disentangling natural variability from the anthropogenic climate change (16).

Although both WBCs have experienced significant warming during recent decade (18), tight linkages between the Gulf Stream and the Kuroshio have never been discovered. More than a decade ago, a monograph by Kelly and Dong (2004) (19) found a hint of the WBC covariability in the upper ocean heat content data. They estimated that $26 \%$ of heat content variations over the entire North Atlantic and Pacific were in phase. Nevertheless, because the data length and the spatial resolution were limited at that time, it was difficult to detect a fine structure or well-defined covariability between the two WBCs. Though some climatologists mentioned this potential WBC covariability as an outstanding issue (2), their monograph is, to the best of our knowledge, the only observational effort that was taken to explore a possible linkage between the Gulf Stream and the Kuroshio.

In the present day, satellite-based high-resolution SST data records $(20,21)$ have become long enough to begin thorough analyses in this vein. The SST distribution in early 2018 may 
a) Sea surface temperature (SST) anomalies (January-June, 2018)

$\left({ }^{\circ} \mathrm{C}\right)$

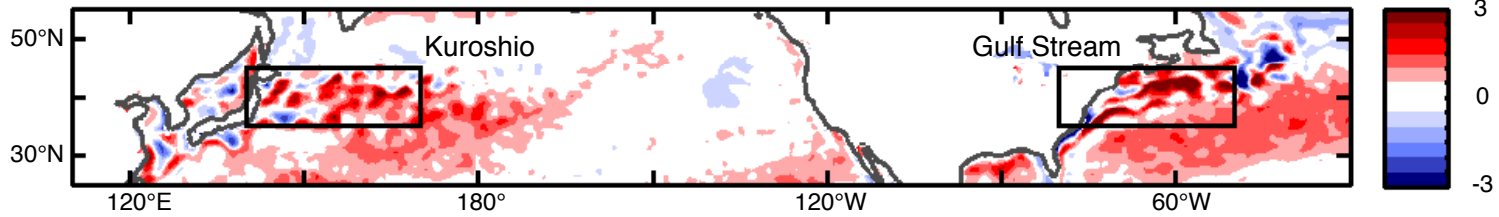

b) Low-pass filtered time series and the BCS index

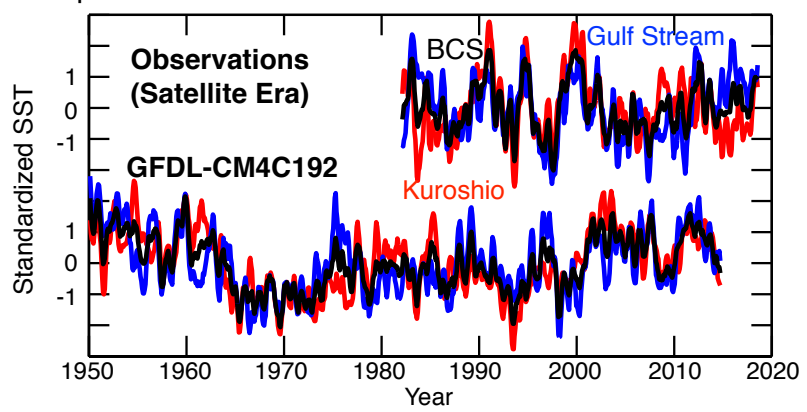

d) Lag Correlations

c) Coherence spectra
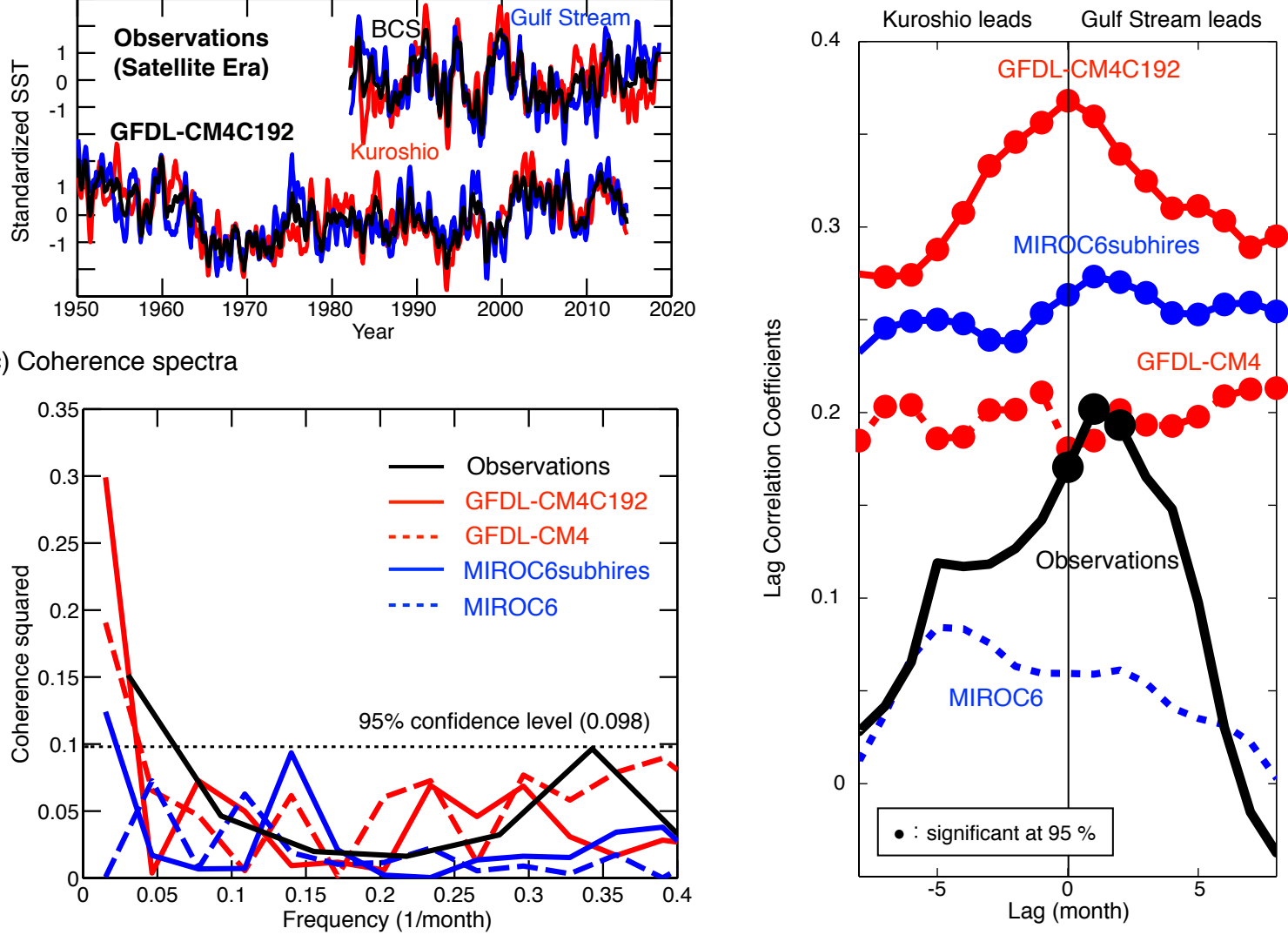

Figure 1: (a): Sea surface temperature (SST) anomalies averaged from January through June, 2018. Boxes show the locations of the two western boundary currents (WBCs). (b): Top, The observed BCS index (black) and five-month running-meaned, standardized SST anomaly time series averaged over the Gulf Stream $\left(35^{\circ} \mathrm{N}-45^{\circ} \mathrm{N}, 80^{\circ} \mathrm{W}-50^{\circ} \mathrm{W}\right)$ (blue dashed) and the Kuroshio $\left(35^{\circ} \mathrm{N}-45^{\circ} \mathrm{N}, 140^{\circ} \mathrm{E}-170^{\circ} \mathrm{E}\right)$ (red dashed) regions defined as the boxes in (a). Bottom, As in top, but for a high-resolution global climate model (GCM). (c): Coherence spectra between the two SST anomaly time series averaged over the Gulf Stream and Kuroshio regions. The black line is observed data, the solid red and blue lines are from high-resolution GCMs, and the dashed lines are from low-resolution GCMs. The statistical significance calculated based on Amos and Koopmans (1963) (17) is shown as the black dotted line. (d): As in (c), but lag correlation coefficients. Positive lags means that Gulf Stream leads Kuroshio. Statistically significant correlations are shown as filled circles. 
initiate speculations about a linkage between the two WBCs (Fig. 1a). During this time span, SSTs near both of the WBC regions are warmer by about $3-5^{\circ} \mathrm{C}$ than the temporal mean over the past four decades, which corresponds to 2-3 standard deviations. This simultaneous warm event would be rarely experienced by random chance. One could attribute these record-breaking warm currents partly to the increasing greenhouse gas forcing, but this explanation appears not to be the whole story as we shall see.

In this study, we show that the regional-mean SSTs over the two ocean currents are synchronized for interannual to decadal time scales. First, the synchronization of the WBCs is statistically demonstrated based on observed and modeled data analyses. Next, we define an index to capture this covariability, as well as highlighting the impact of ocean resolutions on the fidelity of simulated synchronization. Then, the physical mechanism is investigated based on model experiments. Lastly, implications of this phenomenon are discussed.

\section{Statistical demonstration of the Boundary Current Synchronization (BCS) Simple re-} gional mean SST time series are sufficient to suspect the existence of covariability between the two warm currents. In Fig. 1b, based on satellite observations and output from a high-resolution global climate model (GCM), GFDL-CM4C192, we plot five-month running-meaned, standardized time series of regional-mean SST anomalies over the Gulf Stream $\left(35^{\circ} \mathrm{N}-45^{\circ} \mathrm{N}, 80^{\circ} \mathrm{W}\right.$ $\left.50^{\circ} \mathrm{W}\right)$ and the Kuroshio $\left(35^{\circ} \mathrm{N}-45^{\circ} \mathrm{N}, 140^{\circ} \mathrm{E}-170^{\circ} \mathrm{E}\right)$ regions. We hereafter investigate this covariability by referring to it as the Boundary Current Synchronization (BCS).

Both in observations and high-resolution GCMs, the SSTs averaged over the two regions exhibit significant coherence at the $95 \%$ confidence level only in frequencies lower than 0.05 /month (Fig. 1c). Here we plot the squared coherences for observations and four GCMs. GFDLCM4C192, which has finer atmospheric resolution than GFDL-CM4, exhibits higher coherence at low frequency. MIROC6, which has lower oceanic resolution than MIROC6subhires, does 
not exhibit a statistically significant coherence throughout all frequencies.

The SST variations are almost simultaneous between the two currents. In Fig.1d, we plot lag correlations of the regional-mean SST anomalies between the two western boundary current regions for observations and the four GCMs. As to observations, GFDL-CM4C192, and MIROC6subhires, the highest correlations are realized within one-month lag between the two regions, and they are both significant at the $95 \%$ confidence level. In observations and MIROC6subhires, though Gulf Stream leads Kuroshio by one month, this small lag is not significant considering the time scale of the phenomenon. By contrast, correlations in the low resolution models are lower than observations and high resolution models (indeed, correlations in MIROC6 are not significant at the 95\% confidence level), and no strong peak at zero-lag is detected.

\section{Definition of the BCS index and its dependence on spatial resolution We define the BCS} index as the average of the low-pass filtered, standardized regional-mean SST anomalies over the Gulf Stream $(\tilde{G})$ and the Kuroshio $(\tilde{K})$ regions, i.e., BCS $\equiv(\tilde{G}+\tilde{K}) / 2$ where a tilde denotes performing a five-month running-mean filter and then normalizing by its own standard deviation. As shown in Fig. 1b, the BCS index captures the temporal variations of SST over both the Gulf Stream and the Kuroshio regions for both observations and models.

One might suspect that the regions used to define the index are too subjective and too large to capture specific features of the boundary currents, and that they might reflect SST variability in broader regions, rather than the currents themselves. Therefore, to present counterargument, here we verify that the BCS index is almost equivalent to more objective and precise time series that highlights variability of the boundary currents. In Fig. 2, we show the results from the singular value decomposition (SVD) analysis between SST fields in the western North Pacific and Atlantic regions. This analysis, which is also known as the maximum covariance analysis, 
a) GFDL-CM4C192
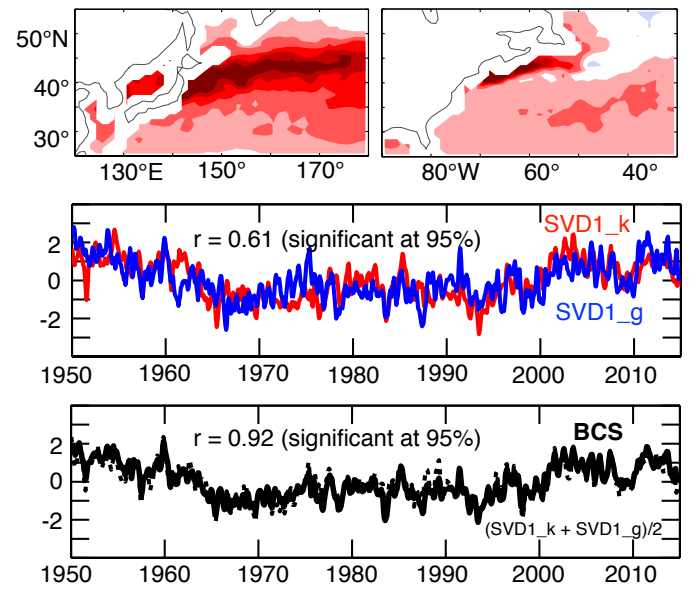

c) GFDL-CM4
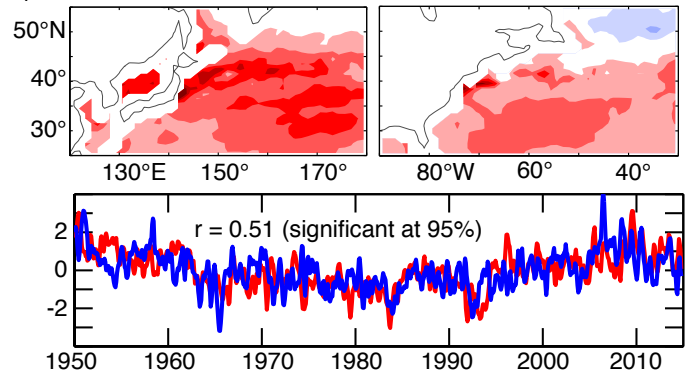

b) MIROC6subhires
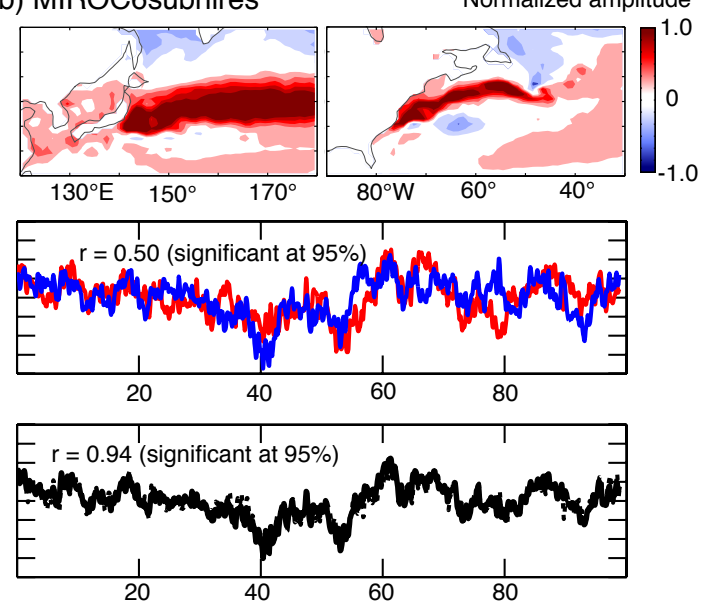

d) MIROC6

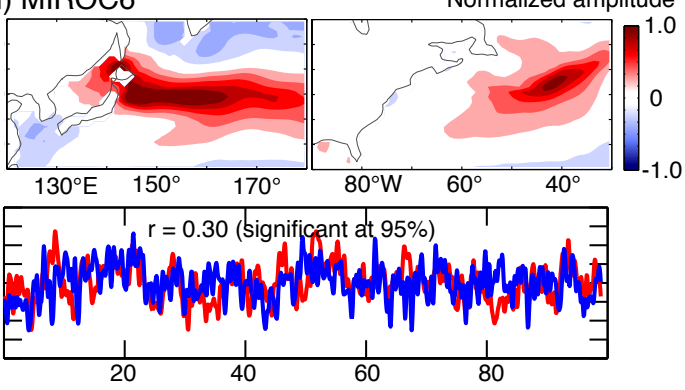

Figure 2: (a): Top, SST patterns of GFDL-CM4C192 extracted as the first mode of the singular value decomposition (SVD1) between the northwest Pacific $\left(25^{\circ} \mathrm{N}-55^{\circ} \mathrm{N}, 120^{\circ} \mathrm{E}-180^{\circ}\right)$ and the northwest Atlantic $\left(25^{\circ} \mathrm{N}-55^{\circ} \mathrm{N}, 90^{\circ} \mathrm{W}-30^{\circ} \mathrm{W}\right)$ regions. Middle, Projected SST time series onto SVD1 for the northwest Pacific $\left(\mathrm{SVD} 1_{k}\right.$ ) and the northwest Atlantic (SVD1 $1_{g}$ ). Three-month running-mean flitering is performed. Also shown are the correlation coefficient $r$ between the two time series and its statistical significance. Bottom, As in middle, but the BCS index (solid) and the average of $\mathrm{SVD}_{k}$ and $\mathrm{SVD}_{g}$ (dashed). (b): As in (a), but for MIROC6subhires. (c): As in (a), but for GFDL-CM4. The bottom panel is omitted. (d): As in (c), but for MIROC6. 
extracts the SST patterns that maximize the covariance between the two projected time series.

In two out of three models with eddy-permitting oceanic resolutions (i.e., GFDL-CM4C192 and MIROC6subhires), the first SVD (SVD1) mode captures SST variability of the narrow boundary currents (Figs. 2a and 2b). The two projected time series exhibit statistically significant correlations of 0.61 and 0.50 for GFDL-CM4C192 and MIROC6subhires, respectively, which confirms the suitability to perform SVD for these particular fields. Moreover, the mean of the two projected time series exhibit a correlation larger than 0.9 with the BCS index. This high correlation assures us that the simple definition of the BCS index is virtually identical to a more objectively-defined index that reflects the temperature variations confined to the narrow boundary current regions.

The SVD1 of GFDL-CM4, which also has an eddy-permitting ocean but has a coarser atmosphere than GFDL-CM4C192, does not capture boundary currents well (Fig. 2c). Based on this result, the low correlations shown in Fig. 1d is due to the ill-defined SST fronts that originate from the coarse atmospheric resolution. In MIROC6, which does not resolve oceanic eddies, the SVD1 does not capture the narrow boundary currents at all (Fig. 2d). Though the projected time series exhibit significant correlations, the correlations are lower than the high-resolution counterparts. This low correlations support a notion that high resolution models that adequately resolve mesoscale eddies and their interactions with the atmosphere are essential for an accurate representation of BCS. The BCS index represents boundary current variability only when the spatial grids have sufficiently high resolutions in both atmospheric and oceanic components.

Though we have also performed the same analysis based on observations, SST variability is captured clearly only in the Kuroshio, and that of the Gulf Stream is more subtle (Fig. S1, top). This failure could be because the length of the data record over the satellite era is insufficient for this particular analysis. Nevertheless, it is still notable that the SVD1 time series exhibit statistically significant correlation of 0.49 (Fig. S1, bottom), which means that almost a quarter 
variance of the first mode in these regions are explained by each other.

Dynamical and thermodynamical manifestations of BCS Meridional migrations of the tropospheric westerly jet stream serve as an essential component of BCS. The regression map of observed SST and zonal winds on the BCS index shows that, when the boundary current regions are anomalously warm, the tropospheric jet stream tends to migrate northward, and vice versa (Fig. 3a). The same relationship is reproduced by MIROC6subhires (Fig. 3b). Considering that the two ocean currents are separated by the North American continent, they cannot exchange heat via oceanic pathways within the decadal time scale. Therefore, it is virtually certain that the atmospheric jet stream ties temperature variations of two distant ocean currents.

Wind-driven ocean dynamics, in addition to thermodynamical processes, is of first-order importance for BCS. The composite maps of geostrophic current strength anomalies show that, when the BCS index is positive, the positions for the boundary currents to be separated from the shores tend to shift northward, and vice versa (Fig. 3c). For example, when BCS reaches +2 standard deviations, the Gulf Stream is separated from the North American continent near the Virginia state $\left(38^{\circ} \mathrm{N}\right)$. By contrast, when BCS reaches -2 standard deviations, the Gulf Stream is diverted eastward near the South Carolina state $\left(32^{\circ} \mathrm{N}\right)$. Similarly, the "ripping point" of the Kuroshio also varies meridionally from the Iwate prefecture $\left(40^{\circ} \mathrm{N}\right)$ to the Aogashima island $\left(32^{\circ} \mathrm{N}\right)$, depending on the phase of BCS.

This meridional shifts of the current pathways are consistent with the temperature variations shown in Fig. 3b, considering that both the Gulf Stream and the Kuroshio transport warm water from the tropics. A positive BCS event lets the boundary currents convey more heat to the north, whereas a negative BCS event keeps heat to stay in the south.

Because BCS is associated with the low-frequency behavior of the atmospheric jet stream, BCS has its implication for the midlatitude extreme weather. The spatial pattern of surface 
a) Observed SST and lower tropospheric zonal wind regressed on BCS

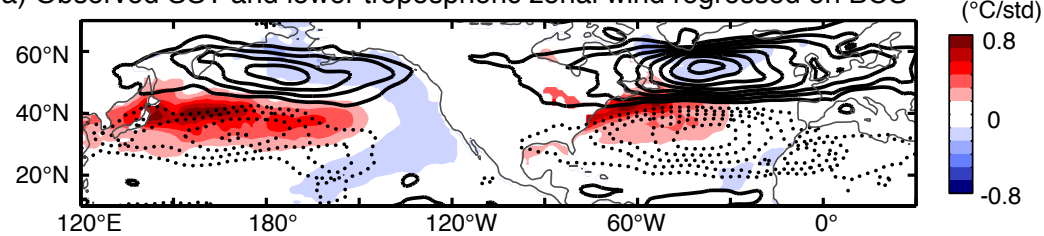

b) As in a) but for MIROC6subhires

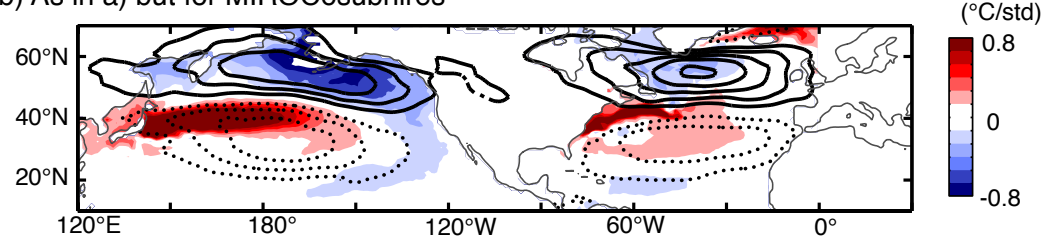

c) Geostrophic current strength $(I \nabla($ sea level)I) and its anomalies, MIROC6subhires

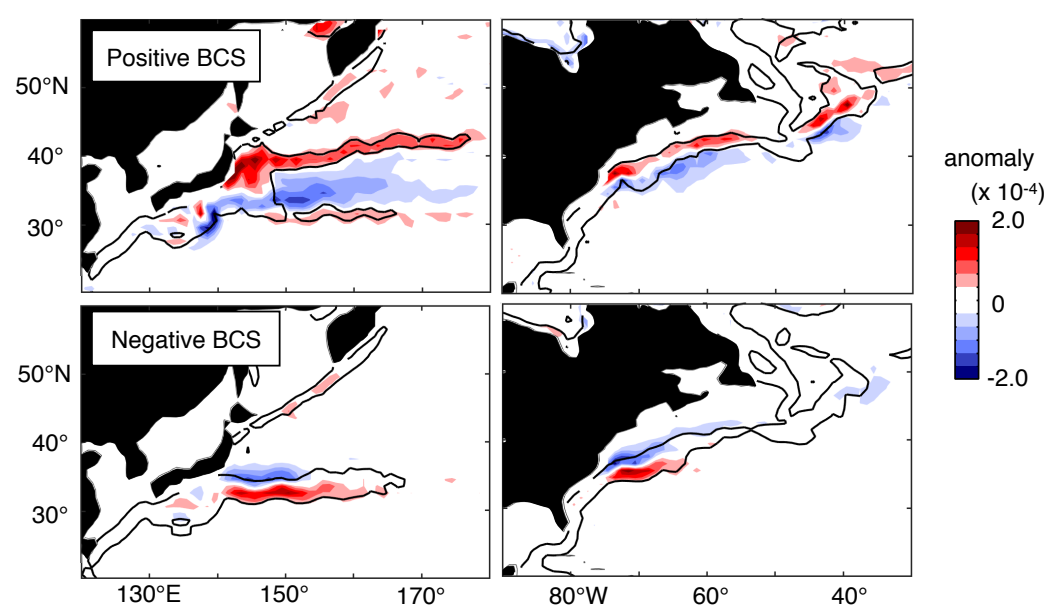

d) 2-meter air temperature anomalies (July, 2018)

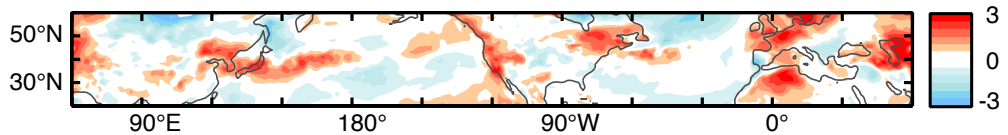

e) 2-meter air temperature in July regressed on the BCS index $\quad\left({ }^{\circ} \mathrm{C} / \mathrm{std}\right)$

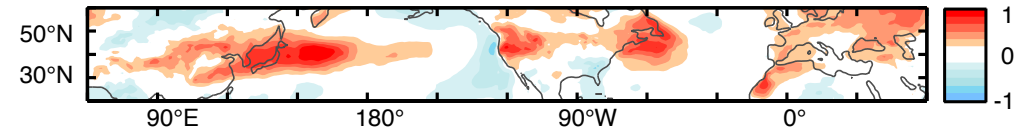

Figure 3: (a): Observed anomalies of SST (shaded areas) and zonal winds (contours) at 850 $\mathrm{hPa}$ regressed on the BCS index. Contour interval is $0.15(\mathrm{~m} / \mathrm{s}) / \mathrm{std}$. Solid (dashed) contours show positive (negative) anomalies, and zero contours are omitted. (b): As in (a), but for the MIROC6subhires model. (c): Composite maps of geostrophic current strength (contours) and its anomalies (shaded areas), which is estimated as anomalies of the absolute value of gradient of the sea level, for extremely positive (top) and negative (bottom) BCS events. Extreme BCS events are defined as the months when the BCS index exceeds its \pm 2 standard deviations. Contour interval is $1.2 \times 10^{-4}$. (d): Monthly-mean surface temperature anomalies for July 2018 . (e): 2-meter air temperature anomalies in July regressed on the BCS index calculated using the July-only data. 
temperature anomalies observed in July 2018 (Fig. 3d) corresponds well to the regression map of 2-meter air temperature anomalies on the BCS index calculated using the July-only data (Fig. 3e). East Asia, the west and east coasts of North America, Europe, and Northwest Africa experienced a hot summer in 2018, and these features are typical anomalies associated with positive BCS events.

Model experiments Many previous studies convincingly showed possible physical processes of interactions between large-scale tropospheric winds and WBCs $(3,7,22-24)$. In particular, at the beginning of this century, a possibly-related theoretical work was presented by Gallego and Cessi (2001) (GC01) (25). They developed an idealized model of two ocean basins, each having its own WBC, whose stream function is determined through the time-dependent Sverdrupbalance (Fig. 4a). In their model, the two WBCs are coupled to each other only through the zonally-symmetric atmosphere.

The idealized model by GC01 illustrates possible mechanisms of WBC covariability via wind stress and heat fluxes, and theoretically predicts existence of a chaotic regime that exhibits BCS-like variability. Using a modified version of the GC01 model with realistic choices of parameters (see Data and Methods), the observed synchronicity of the two strengthening WBCs and the westerly jet are reproduced (Fig. 4b). In particular, this conceptual model predicts that the warm phase of WBCs are associated with a northward shift of jet stream and vice versa, which is consistent with observations and the high-resolution GCMs. (Fig. 4c). As a promising candidate to explain BCS, this model presents a physical process where zonally-symmetric atmosphere synchronizes the Pacific and Atlantic Oceans with different intrinsic frequencies by mediating the information of the two ocean currents. This inter-basin coupling mechanism is also consistent with Omrani et al. (2019) (26), who showed, using semi-idealized atmospheric general circulation models (AGCMs), that forcings from both Kuroshio and Gulf Stream are 


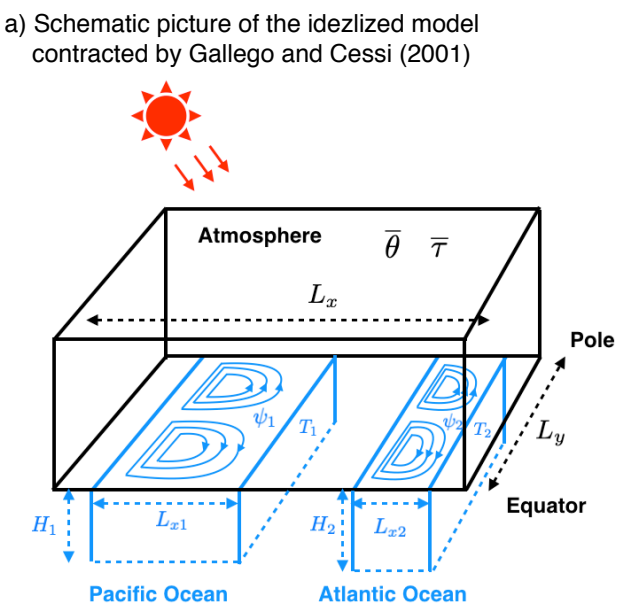

b) Modeled and observed time series of boundary currents and winds
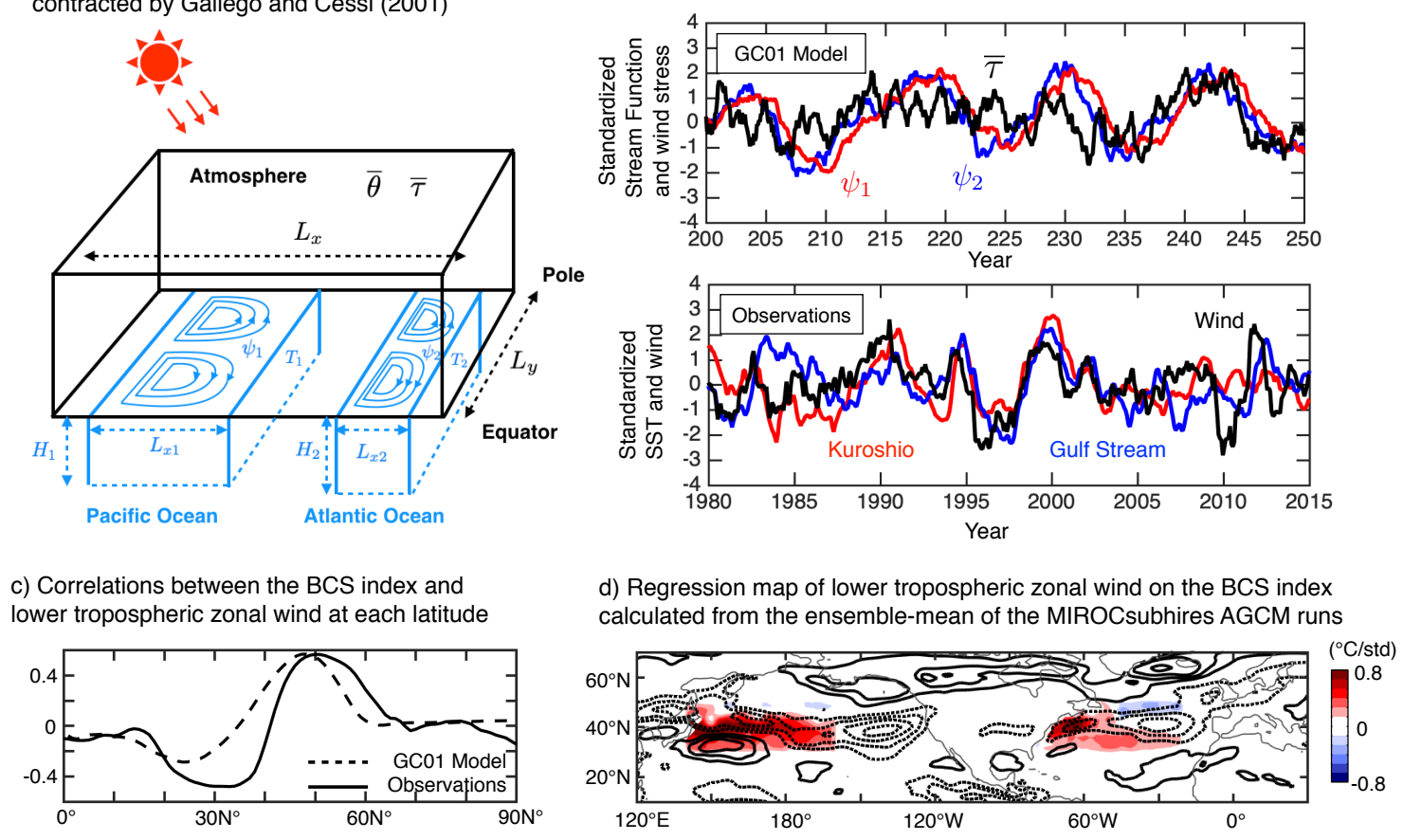

Figure 4: (a): Schematic diagram of the idealized model formulated by Gallego and Cessi (2001) (GC01). (b): Top, Modeled stream function anomalies $\psi_{1}$ (red) and $\psi_{2}$ (blue) at 4,000 $\mathrm{km}$ north of the southern boundary. Also shown in black is zonal-mean westerly wind stress $(\bar{\tau})$ anomalies at 5,200 $\mathrm{km}$ north of the equator. Bottom, Observed SST anomaly time series averaged over the Gulf Stream $\left(35^{\circ} \mathrm{N}-45^{\circ} \mathrm{N}, 80^{\circ} \mathrm{W}-50^{\circ} \mathrm{W}\right)$ (blue) and the Kuroshio $\left(35^{\circ} \mathrm{N}-45^{\circ} \mathrm{N}\right.$, $140^{\circ} \mathrm{E}-170^{\circ} \mathrm{E}$ ) (red) regions. Also shown in black is observed zonal-mean zonal wind at 850 $\mathrm{hPa}$ averaged over the Northern Pacific and Atlantic $\left(45^{\circ} \mathrm{N}-60^{\circ} \mathrm{N}, 140^{\circ} \mathrm{E}-0^{\circ}\right)$. Each time series is normalized by its own standard deviation. (c): Solid, Observed correlation coefficients between the BCS index and 11-month running-meaned zonal wind at $850 \mathrm{hPa}$ zonally-averaged over the Pacific and the Atlantic $\left(140^{\circ} \mathrm{E}-0^{\circ}\right)$. Dashed, As in the solid curve, but between modeled temperature averaged over the two basin $\left(\left(\overline{T_{1}}+\overline{T_{2}}\right) / 2\right)$ and the zonal wind stress $(\bar{\tau})$. The southern (northern) boundary of the model is set to be $20^{\circ} \mathrm{N}\left(90^{\circ} \mathrm{N}\right)$. (d): As in Fig. 3a, but for the ensemble-mean of the MIROCsubhires AGCM runs with SST anomalies added to climatology in the Kuroshio and Gulf Stream regions. Contour interval is $0.08(\mathrm{~m} / \mathrm{s}) / \mathrm{std}$. 
necessary to maintain the zonally quasi-symmetric Northern Annular Mode variability.

To quantify the role of SST forcings, we have also performed an AGCM experiment. Figure $4 \mathrm{~d}$ shows the regression map of zonal wind at $850 \mathrm{hPa}$ on the BCS index calculated from the ensemble-mean of the MIROCsubhires AGCM runs with observed SST anomalies added to the model climatology only in the Kuroshio and Gulf Stream regions ("BCS experiment"; see Data and Methods). This AGCM experiment is designed to capture a strongly positve BCS event. As a forced response to warm western boundary current SST anomalies, the jet stream is shifted northward. Similar results are obtained by subtracting zonal winds of the control experiment from those of the BCS experiment.

These results qualitatively support the air-sea coupled mechanism proposed by GC01 in the sense that zonally-symmetric atmospheric variability is forced by SST anomalies in the western boundary regions, which in turn feeds back to the ocean through dynamical and thermodynamical processes. In this regard, our additional sensitivity experiments using the GC01 model show that, when the dynamical (thermodynamical) coupling is artificially removed, correlations between the Gulf Stream and the Kuroshio decline from 0.84 to 0.26 (0.41) (Fig. S2). This result suggests that both dynamical and thermodynamical coupling mechanisms could play fundamental roles in BCS (see also Data and Methods and several previous studies (27-30)).

Quantitatively, however, zonal wind anomalies simulated by our AGCM experiment are weaker than those of observations and the air-sea coupled model experiments. This small magnitude of the anomalies can at least be explained by following two reasons. First, air-sea coupled mechanisms, which are in principle not incorporated in an AGCM experiment, can amplify the BCS variability. For example, air-sea couplings between the storm track and the northern hemispheric WBCs (31) could enhance atmospheric variability to realize a realistic BCS amplitude. Similarly, air-sea coupling processes could also operate for locating the SST front to an optimum position where surface heating can enhance the persistence of the atmospheric intrinsic 
variability (32). Second, as is also discussed in Smirmov et al. (2015) (33), the resolution of observational SST data that are added to the lower boundary condition of the AGCM could be too coarse to capture the full role of SST fronts. As shown in previous sections, GCMs with high spatial resolution exhibit statistically significant BCS variability, whereas those with low-resolution do not. This result is consistent with a notion that sharp SST fronts are another essential ingredient of BCS, in addition to the inter-basin coupling mechanism proposed by GC01. By adding idealized SST fronts to an AGCM experiment, Ogawa et al. (2012) (34) also showed that the meridional position of the eddy-driven jet can be anchored by the SST fronts.

Implications Understanding BCS have immediate implications for human lives, because the Gulf Stream and the Kuroshio transport heat from the tropics to the extratropics, and their temperature variations affect the extreme weather of densely-populated areas in the northern hemisphere (4-6). The hot summer experienced in 2018 is a good example of extreme weather associated with BCS (Figs. 3d and 3e). In particular, because other prominent climate modes (e.g., the El Niño Southern Oscillation) were relatively inactive in 2018, the BCS signature may have clearly emerged in the observed air temperature over the entire northern hemispheric extratropics.

BCS also have implications for fisheries productions because the variability of western boundary currents modulates marine ecosystems (35-38). Warm SST associated with a northward shift of the Gulf Stream increases the mortality of Atlantic cod (Gadus morhua) (35), whereas migrations of pelagic fish, such as Japanese sardine (Sardinops melanostictus) (36) and Pacific saury (Cololabis sairai) $(37,38)$, are influenced by the Kuroshio variability because they use the Kuroshio region as spawning and nursery grounds (39). Continuous monitoring of the two WBCs with a finer observational network, as well as development of high resolution GCMs are necessary for accurate understanding and prediction of BCS in a changing climate. 


\section{References}

1. N. G. Hogg, W. E. Johns, Rev. Geophys. 33, 1311 (1995).

2. Y.-O. Kwon, et al., J. Climate 23, 3249 (2010).

3. K. A. Kelly, et al., J. Climate 23, 5644 (2010).

4. F. Sanders, Mon. Wea. Rev. 114, 1781 (1986).

5. G. S. Young, T. D. Sikora, Mon. Wea. Rev. 131, 2177 (2003).

6. S. Minobe, A. Kuwano-Yoshida, N. Komori, S.-P. Xie, R. J. Small, Nature 452, 206 (2008).

7. H. Nakamura, et al., J. Oceanogr. 71, 463 (2015).

8. R. Masunaga, H. Nakamura, H. Kamahori, K. Onogi, S. Okajima, SOLA 14, 6 (2018).

9. M. Latif, T. P. Barnett, Science 266, 634 (1994).

10. M. Latif, T. P. Barnett, J. Climate 9, 2407 (1996).

11. H. Nakamura, G. Lin, T. Yamagata, Bull. Amer. Meteor. Soc. 78, 2215 (1997).

12. R. Zhang, Geophys. Res. Lett. 35 (2008).

13. N. J. Mantua, S. R. Hare, Y. Zhang, J. M. Wallace, R. C. Francis, Bull. Amer. Meteor. Soc. 78, 1069 (1997).

14. M. Yamamoto, T. Oba, J. Shimamune, T. Ueshima, Geophys. Res. Lett. 31 (2004).

15. A. Paul, C. Schäfer-Neth, Paleoceanogr. 18 (2003).

16. R. C. Wills, T. Schneider, J. M. Wallace, D. S. Battisti, D. L. Hartmann, Geophys. Res. Lett. 45, 2487 (2018). 
17. D. E. Amos, L. H. Koopmans, Tables of the distribution of the coefficient of coherence for stationary bivariate Gaussian processes, vol. 483 (Sandia Corporation, 1963).

18. L. Wu, et al., Nature Climate Change 2, 161 (2012).

19. K. A. Kelly, S. Dong, Earth's Climate: The Ocean-Atmosphere Interaction, Geophys. Monogr 147, 347 (2004).

20. R. W. Reynolds, et al., J. Climate 20, 5473 (2007).

21. D. P. Dee, et al., Quart. J. Roy. Meteor. Soc. 137, 553 (2011).

22. R. Seager, Y. Kushnir, N. H. Naik, M. A. Cane, J. Miller, J. Climate 14, 4249 (2001).

23. M. Nonaka, S.-P. Xie, J. Climate 16, 1404 (2003).

24. X. Ma, et al., Nature 535, 533 (2016).

25. B. Gallego, P. Cessi, J. Climate 14, 2815 (2001).

26. N.-E. Omrani, et al., Sci. Rep. 9, 3014 (2019).

27. C. Frankignoul, P. Müller, E. Zorita, J. Phys. Oceanogr. 27, 1533 (1997).

28. F.-F. Jin, J. Climate 10, 1821 (1997).

29. R. Saravanan, J. C. McWilliams, J. Climate 11, 165 (1998).

30. S. Kravtsov, W. K. Dewar, P. Berloff, J. C. McWilliams, M. Ghil, Dyn. Atmos. Oceans 43, $123(2007)$.

31. B. J. Hoskins, P. J. Valdes, J. Atmos. Sci. 47, 1854 (1990).

32. S. Peng, W. A. Robinson, J. Climate 14, 2943 (2001). 
33. D. Smirnov, M. Newman, M. A. Alexander, Y.-O. Kwon, C. Frankignoul, Journal of Climate 28, 1126 (2015).

34. F. Ogawa, H. Nakamura, K. Nishii, T. Miyasaka, A. Kuwano-Yoshida, Geophys. Res. Lett. 39 (2012).

35. A. J. Pershing, et al., Science 350, 809 (2015).

36. Y. Watanabe, H. Zenitani, R. Kimura, Can. J. Fish. Aquat. Sci. 53, 55 (1996).

37. S.-i. Saitoh, S. Kosaka, J. Iisaka, Deep Sea Res. Part A. Oceanogr. Res. Pap. 33, 1601 (1986).

38. Y. Tian, T. Akamine, M. Suda, Fisheries research 60, 439 (2003).

39. H. Kuroda, et al., Open J. Marine Sci. 7, 62 (2016).

40. V. Eyring, et al., Geosci. Model Dev. 9 (2016).

41. I. Held, et al., J. Adv. Model. Earth Syst. 11, 3691 (2019).

42. H. Tatebe, et al., Geosci. Model Dev. 12, 2727 (2019).

43. H. Tatebe, M. Watanabe, MIROC MIROC6 model output prepared for CMIP6 CMIP picontrol (2018).

44. C. S. Bretherton, M. Widmann, V. P. Dymnikov, J. M. Wallace, I. Bladé, J. Climate 12, 1990 (1999).

Acknowledgments The first author is supported by JSPS-Kakenhi Grant Number 19K23460 and 20K14554. The second, fifth, and sixth authors were supported by the Integrated Research Program for Advancing Climate Models (TOUGOU) Grant Number JPMXD0717935457 from 
the Ministry of Education, Culture, Sports, Science and Technology (MEXT), Japan. The third author is supported by JSPS-Kakenhi Grant Number 16H04048. The fourth author was supported by JSPS-Kakenhi Grant Number 17J04384. We would like to thank Yukio Masumoto and Tomoki Tozuka for useful discussion.

Data and Methods Observed SST data is downloaded from the National Oceanic and Atmospheric Administration (NOAA) Optimum Interpolation SST (OISST) (20) available at https : //www.esrl.noaa.gov/psd/data/gridded/data.noaa.oisst.v2.highres. html. Observational zonal wind fields at $850 \mathrm{hPa}$ and 2-meter air temperature (July only) are from the European Center for Medium range Weather Forecasting (ECMWF) ERA-Interim reanalysis data (21) at http: / / apps.ecmwf.int/datasets/data/interim-full-moda/ levtype=sfc/. The resolution of the OISST and ERA-Interim data sets used in this study is $1^{\circ}$ in both longitudes and latitudes. The time span used in this study is from December 1981 through September 2018.

The SST output of the GFDL models is from the Coupled Model Intercomparison Project Phase 6 (CMIP6) data (40) available at the website of the World Climate Research Programme (https://esgf-node.llnl.gov/search/cmip6/). The experiment considered in this study is the first ensemble member of historical runs, which includes "historical" for CMIP6 for GFDL-CM4 and "hist-1950” (HighResMIP) for GFDL-CM4C192. GFDL-CM4 consists of atmosphere and land models at about $100 \mathrm{~km}$ horizontal resolution and ocean and sea ice models at roughly $25 \mathrm{~km}$ horizontal resolution, whereas GFDL-CM4C192 has a higher atmospheric spatial resolution (roughly $50 \mathrm{~km}$ resolution). For more detailed description of the GFDL models, see Held et al. (2019) (41). The time span used in this study is from January 1950 through December 2014. For data analysis, the data is regridded via linear interpolation onto a $1^{\circ}$ longitude by $1^{\circ}$ latitude grid so it matches that of observational products. 
In addition to the downloaded output from GFDL models, two kinds of state-of-the-art climate models are used in the present study. One is the sixth version of Model for Interdisciplinary Research on Climate (hearafter, MIROC6) which has been cooperatively developed by a Japanese modeling community (42). The atmospheric and land surface components of MIROC6 have horizontal resolution of a T85 spectral truncation. The model top of the atmospheric component is placed to $0.004 \mathrm{hPa}$, and there are 81 vertical levels. The governing equations for the ocean and sea-ice components are discretized on tripolar horizontal coordinate system with the resolution of nominal $1^{\circ}$, and there are 62 vertical levels. MIROC6 is spun up for 1000 years with the preindustrial external forcing dataset following the protocol of the sixth phase of the Coupled Model Intercomparison Project (CMIP6; (40)). After the model climate reaches thermally and dynamically quasi-equilibrium state, additional 1000-year-long integration is performed, and the last 100-year-long data of the preindustrial control simulation is analyzed in the present study. The readers may refer to Tatebe et al. (2019) (42) for detailed description and evaluation of MIROC6. The model data are distributed as Tatebe and Watanabe (2018) (43) through the Earth System Grid Federation and are freely accessible. The other is MIROC6subhires whose atmospheric and land surface components are the exactly same as MIROC6 but the oceanic component is replaced by a horizontal higher-resolution version with nominal $0.25^{\circ}$ grid spacings in both of zonal and meridional directions. Because oceanic mesoscale eddies and fronts are modestly resolved, a few parameterizations for subgrid horizontal and isopycnal diffusion processes are set to be less effective in MIROC6subhires than in MIROC6. MIROC6subhires is spun up for 700 years with initial conditions taken from the preindustrial control simulation and the same external forcing dataset of MIROC6. After the model climate reaches a quasi-equilibrium state, additional 200-year-long integration is performed. The last 100-year-long data is analyzed in the present study.

To calculate detrended anomalies, we subtract monthly climatology (i.e., means of each 
calendar month) and linear trends. The statistical significance of correlations is tested by the two-tailed Student's t-test. To estimate statistical degrees of freedom in auto-correlated time series, we employ a formula to calculate the effective sample size proposed by Bretherton et al. (1999) (44).

We also conduct two AGCM experiments with 10 ensemble members using the atmospheric component of MIROC6 and MIROC6Subhires. In the control experiment, the AGCM is forced with the monthly climatology of SST and sea ice extent in MIROC6Subhires. Then, to examine the impact of SST anomalies associated with BCS, the BCS experiment is conducted, where observed interannual SST anomalies only in the Kuroshio $\left(140^{\circ} \mathrm{E}-200^{\circ} \mathrm{E}, 30^{\circ} \mathrm{N}-50^{\circ} \mathrm{N}\right)$ and Gulf Stream $\left(80^{\circ} \mathrm{W}-20^{\circ} \mathrm{W}, 30^{\circ} \mathrm{N}-50^{\circ} \mathrm{N}\right)$ regions are superimposed on the SST climatology in the control run. With different initial conditions, each experiment is integrated for five years from 1 January 1992, during which a large BCS index is observed, to investigate the response of the zonal wind to SST anomalies associated with a strongly positive BCS event.

To describe the concept of BCS under a simple framework, we adopt a conceptual model originally proposed by GC01 (25). As its detailed formulation and derivations of model equations have been already given by GC01, here we only provide a brief summary.

The model has two rectangular ocean basins coupled with a zonally periodic atmosphere, as schematically illustrated in Fig. 4a. The atmosphere has zonal and meridional widths of $L_{x}$ and $L_{y}$, respectively, and each ocean basin (basin 1 and 2) has the same meridional extent as the atmosphere. The zonal width of basin $i(i=1,2)$ is $L_{i}=r_{i} L_{x}$, and its mean thermocline depth is given by $H_{i}$. The dynamical and thermodynamical couplings between the atmosphere and ocean are mediated by surface wind stress and air-sea heat flux, as detailed below.

The zonally periodic atmosphere is characterized by two variables, the zonally-averaged surface potential temperature $(\bar{\theta})$ and zonal wind stress $(\bar{\tau})$. By considering conservations of heat and zonal momentum as well as the quasi-geostrophic relation, we obtain the following 
governing equations:

$$
\bar{\theta}=\Gamma\left(\Lambda \overline{\theta_{A}}+r_{1} \lambda \overline{T_{s 1}}+r_{2} \lambda \bar{T}_{s 2}+F f(y)-r_{1} \lambda \sigma_{1} \xi_{1}-r_{2} \lambda \sigma_{2} \xi_{2}\right)+\sigma_{3} \xi_{3}
$$

$$
\frac{\partial \bar{\tau}}{\partial y}=d_{e} \rho_{o} \nu_{o}\left\{\beta\left(y-\frac{L_{y}}{2}\right)+\frac{f_{o}}{S d}\left(\bar{\theta}-\overline{\theta_{A}}\right)\right\}
$$

with $\overline{\theta_{A}}=\frac{F_{0}-A}{B}, f(y)=\cos \left(\frac{\pi y}{L_{y}}\right), \Gamma=\frac{1}{C_{p a} \rho_{o} \nu_{o} d_{e}+B+\left(r_{1}+r_{2}\right) \lambda}, \Lambda=C_{p a} \rho_{o} \nu_{o} d_{e}+B$, and $d_{e}=\frac{D d}{d+D}$. Here, $\overline{T_{s 1}}$ and $\overline{T_{s 2}}$ represent the zonally-averaged SST of basin 1 and 2, respectively, and $\overline{\theta_{A}}$ is the planetary averaged potential temperature. Also, $\rho_{a}=\rho_{o} \exp (-z / D)$ is the atmospheric density ( $D$ is the scale height), $\nu=\nu_{o} \exp (-z / d)$ is the eddy relaxation rate, and $F_{0}+F f(y)$ is prescribed shortwave radiation. In addition, $C_{p a}$ denotes the specific heat of the atmosphere, $f_{o}$ is the Coriolis patemeter, $\beta$ is the planetary beta, $S$ represents the atmospheric stability, and $\lambda$ is the damping coefficient of heat flux. For definition of other parameters and their values, please see Table 1 and GC01. The zonal wind stress, $\bar{\tau}$, is obtained by meridionally integrating Eq. (2) with the boundary condition that $\bar{\tau}=0$ at $y=0$.

To represent atmospheric variability, we introduce three stochastic forcings, $\sigma_{1} \xi_{1}, \sigma_{2} \xi_{2}$, and $\sigma_{2} \xi_{3}$, with $\xi_{i}(i=1,2,3)$ denoting gaussian noise forcings with a zero mean and unit variance. As described in Eqs. (1) and (2), the atmospheric state is determined by zonally-averaged SSTs of the two basins.

The state variables of the ocean model are the zonally averaged SST $\left(=\overline{T_{s i}}\right)$ and interior stream function at the western boundary $\left(=\psi_{W i}\right)$ of each $\operatorname{basin}(i=1,2)$. They are determined by the upper ocean heat budget and linear baroclinic Rossby wave dynamics as follows (28):

$$
\psi_{W i}(y, t)=\frac{R_{i}^{2}}{\rho_{w} H_{i}} \int_{t-\frac{L_{x i}}{c_{i}}}^{t} \frac{\partial \bar{\tau}\left(y, t^{\prime}\right)}{\partial y} d t^{\prime}
$$

$\frac{\partial \overline{T_{s i}}}{\partial t}=\Upsilon_{i} \frac{\partial}{\partial y}\left(\psi_{W i}^{2} \frac{\partial \overline{T_{i}}}{\partial y}\right)-\frac{\lambda \Gamma}{C_{p w} \rho_{w} H_{i}}\left\{\Lambda \overline{T_{i}}+\lambda r_{j}\left(\overline{T_{i}}-\overline{T_{j}}\right)-F f(y)-\lambda r_{i} \sigma_{i} \xi_{i}-\lambda r_{j} \sigma_{j} \xi_{j}\right\}-\frac{\lambda \sigma_{3} \xi_{3}}{C_{p w} \rho_{w} H_{i}}+\epsilon \frac{\partial^{2} \overline{T_{i}}}{\partial y^{2}}$ 
361

with $\Upsilon_{i}=\frac{C_{p w} \rho_{w} H_{i}}{2 \lambda \delta_{i} L_{x i}}$. Here, $R_{i}(i=1,2)$ are the baroclinic radius of deformation of the basin $i$, $c_{i}=\beta R_{i}^{2}$ denote the speed of the long Rossby waves, and $\delta_{i}$ are the zonal widths of frictional western boundary layers. Also, $\rho_{w}$ is the seawater density, $C_{p w}$ represents the specific heat of seawater, and $\epsilon$ is the horizontal diffusivity. Again, values and definitions of these variables are summarized in Table 1. Eq. (3) and (4) demonstrates that the ocean is dynamically forced by the atmosphere via the wind stress $\operatorname{curl}\left(\frac{\partial \bar{\tau}}{\partial y}\right.$; See Eq. (2)) and thermodynamical coupling is mediated by potential temperature $(\bar{\theta})$. Thus, the two-way coupling between the ocean and atmosphere is represented under a concise framework.

Using parameters shown in Table 1, we numerically integrate Eqs. (1)-(4) for 1,000 years with a time step of 0.5 month and discretized with a meridional grid spacing of $1 \times 10^{5} \mathrm{~m}$. This experiment is referred to as the control (CTL) experiments. We have also performed calculations with several different choice of parameters, and obtained similar BCS-like oscillations as demonstrated by GC01.

To understand the roles played by dynamical and themodynamical couplings, we perform two additional sensitivity experiments. In the "NoDYN" experiments, the model is integrated in the same manner as the CTL, except that $\bar{\theta}$ used in the calculation of wind stress curl (Eq. (2) and Eq. (3) is replaced by its time-averaged value derived from the CTL. As ocean currents in the NoDYN experiments do not vary in time, coupling processes mediated by ocean dynamics are completely eliminated. Second, in the "NoTHERM" experiments, we remove thermodynamical interbasin coupling by setting terms involving $j$ in Eq. (4) to their corresponding climatological values (i.e., replace $\overline{T_{j}}$ with the time-averaged derived from the CTL experiment and drop $\xi_{j}$ ). 
Table 1: Parameters used for the conceptual model experiments proposed by GC01.

\begin{tabular}{|c|c|c|}
\hline$L_{x}$ & Zonal width of domain & $2.75 \times 10^{7} \mathrm{~m}$ \\
\hline$L_{y}$ & Meridional width of domain & $1 \times 10^{7} \mathrm{~m}$ \\
\hline$L_{x 1}$ & Zonal width of basin 1 & $8.25 \times 10^{6} \mathrm{~m}$ \\
\hline$L_{x 2}$ & Zonal width of basin 2 & $4.95 \times 10^{6} \mathrm{~m}$ \\
\hline$H_{1}$ & Mean thermocline depth of basin 1 & $300 \mathrm{~m}$ \\
\hline$H_{2}$ & Mean thermocline depth of basin 2 & $300 \mathrm{~m}$ \\
\hline$R_{1}$ & Deformation radius of basin 1 & $5.0 \times 10^{4} \mathrm{~m}$ \\
\hline$R_{2}$ & Deformation radius of basin 2 & $5.0 \times 10^{4} \mathrm{~m}$ \\
\hline$\delta_{1}$ & Width of western boundary layer in basin 1 & $1.0 \times 10^{5} \mathrm{~m}$ \\
\hline$\delta_{2}$ & Width of western boundary layer in basin 2 & $1.0 \times 10^{5} \mathrm{~m}$ \\
\hline$D$ & atmospheric scale height & $1.0 \times 10^{4} \mathrm{~m}$ \\
\hline$\lambda$ & Damping coefficient of heat flux & $50 \mathrm{~W} \cdot \mathrm{m}^{2} \cdot \mathrm{K}^{-1}$ \\
\hline$\rho_{o}$ & Reference density of atmosphere & $1.25 \mathrm{~kg} \cdot \mathrm{m}^{-3}$ \\
\hline$\rho_{w}$ & Reference density of seawater & $10^{3} \mathrm{~kg} \cdot \mathrm{m}^{-3}$ \\
\hline$C_{p a}$ & Specific heat of atmosphere & $1.0 \times 10^{3} \mathrm{~J} \cdot \mathrm{K}^{-1} \cdot \mathrm{kg}^{-1}$ \\
\hline$C_{p w}$ & Specific heat of seawater & $4.0 \times 10^{3} \mathrm{~J} \cdot \mathrm{K}^{-1} \cdot \mathrm{kg}^{-1}$ \\
\hline$\nu_{0}$ & Eddy relaxation parameter & $5.0 \times 10^{-7} \mathrm{~s}^{-1}$ \\
\hline$\epsilon$ & Horizontal diffusivity & $1.0 \times 10^{3} \mathrm{~m}^{2} \cdot \mathrm{s}^{-1}$ \\
\hline$F_{0}-A$ & Heat flux parameter & $37.5 \mathrm{~W} \cdot \mathrm{m}^{-2}$ \\
\hline$B$ & Heat flux parameter & $2.5 \mathrm{~W} \cdot \mathrm{m}^{-2}$ \\
\hline$F$ & Heat flux parameter & $125 \mathrm{~W} \cdot \mathrm{m}^{-2}$ \\
\hline$S$ & Atmospheric stability & $5.0 \times 10^{-3} \mathrm{~K} \cdot \mathrm{m}^{-1}$ \\
\hline$f_{0}$ & Coriolis parameter & $10^{-4} \mathrm{~s}^{-1}$ \\
\hline$\beta$ & Planetary beta & $2.0 \times 10^{-11} \mathrm{~s}^{-1}$ \\
\hline$d_{e}$ & Harmonic average of $d$ and $D$ & $3.68 \times 10^{3} \mathrm{~m}$ \\
\hline$\sigma_{1}$ & Amplitude of gaussian noise forcing (basin 1) & 9.0 \\
\hline$\sigma_{2}$ & Amplitude of gaussian noise forcing (basn 2) & 9.0 \\
\hline$\sigma_{3}$ & Amplitude of gaussian noise forcing (zonal mean) & 5.0 \\
\hline
\end{tabular}




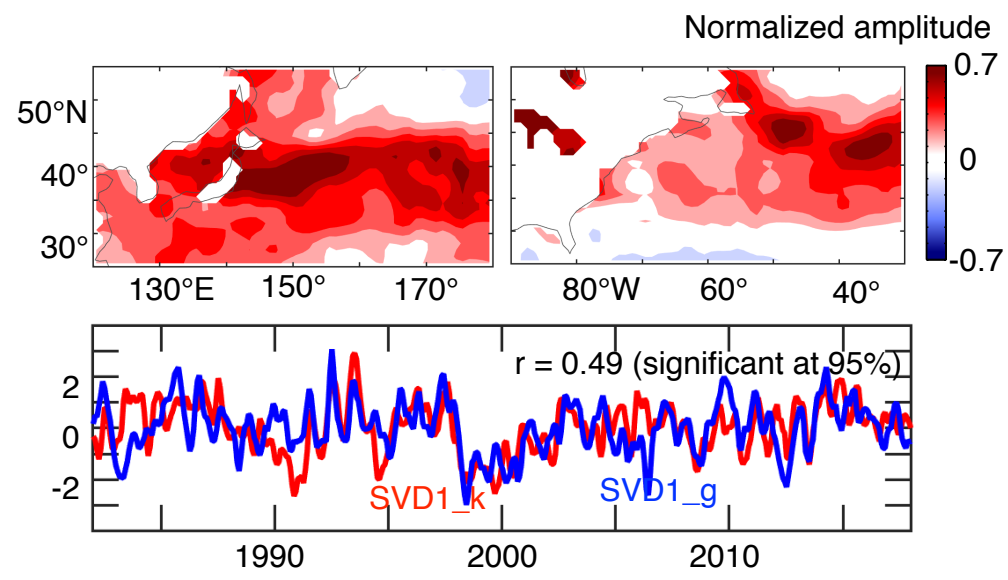

Figure S1: As in Fig. 2, but for observations. 


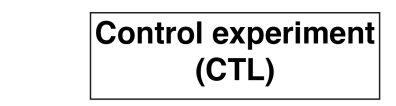

Correlations with Pacific SST

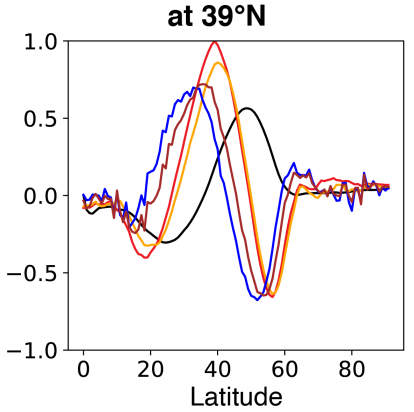

Time series of SST \& wind

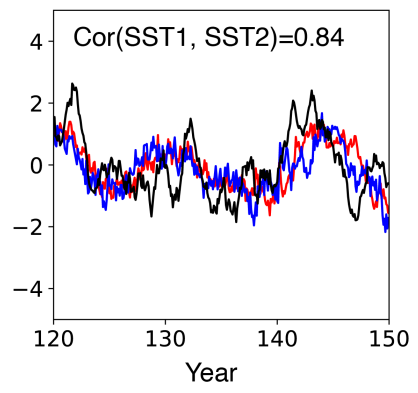

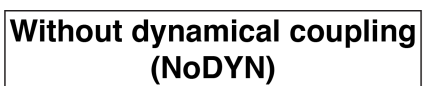

(NoDYN)

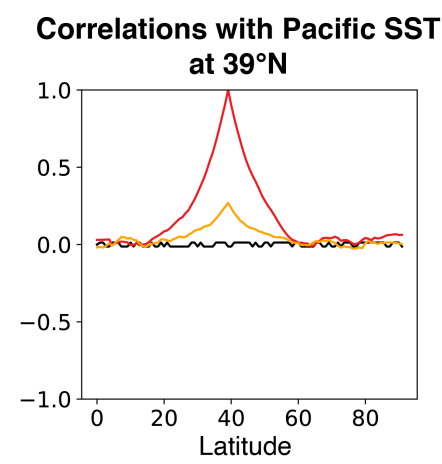

Time series of SST \& wind

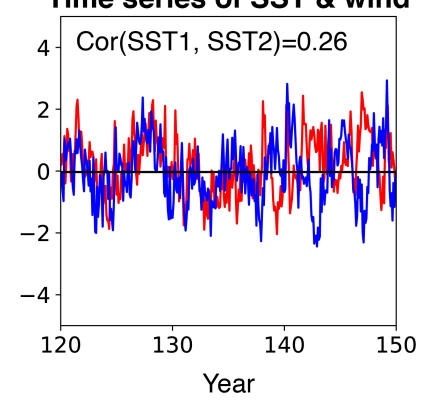

\section{Without thermodynamical coupling}

(NoTHERM)

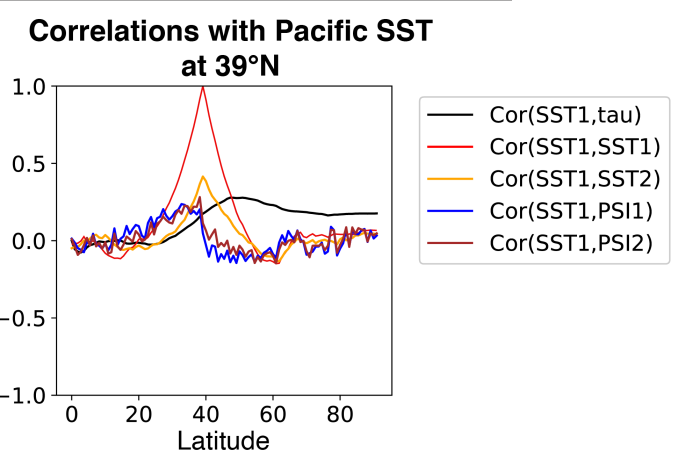

Time series of SST \& wind
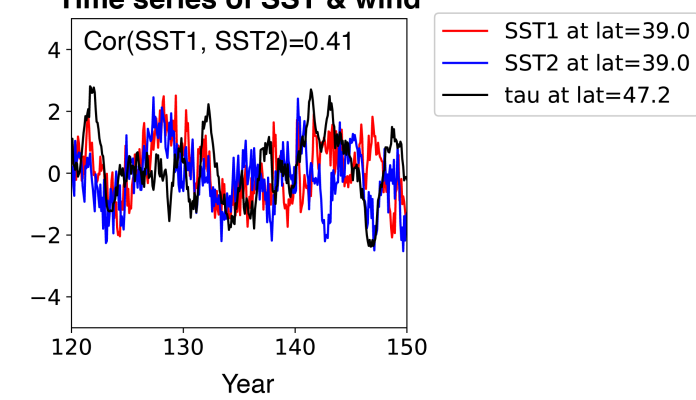

Figure S2: Top, Correlation coefficients between each variable at all latitudes and the Pacific SST anomalies (SST1), $\overline{T_{s 1}}$, at $39^{\circ} \mathrm{N}$. The left, middle, and right panels show the results from the CTL, NoDYN, and NoTHERM experiments, respectively. Bottom, Time series of the Pacific SST anomalies at $39^{\circ} \mathrm{N}$ (red), Atlantic SST anomalies at $39^{\circ} \mathrm{N}$ (blue), and the zonallysymmetric wind stress anomalies at $47.2^{\circ} \mathrm{N}$ (black). Each time series is linearly detrended and normalized by its own standard deviation. Three experiments are shown in the same manner as in the top panels. 